\title{
Hydraulic model calibration using CryoSat2 observations in the Zambezi catchment
}

Kittel, Cécile M. M.; Hatchard, Simbidzayi; Neal, Jeffrey C.; Nielsen, Karina; Bates, Paul D.; Bauer Gottwein, Peter

Published in:

Water Resources Research

Link to article, DOI:

10.1029/2020WR029261

Publication date:

2021

Document Version

Publisher's PDF, also known as Version of record

Link back to DTU Orbit

Citation (APA):

Kittel, C. M. M., Hatchard, S., Neal, J. C., Nielsen, K., Bates, P. D., \& BauerGottwein, P. (2021). Hydraulic model calibration using CryoSat2 observations in the Zambezi catchment. Water Resources Research, 57(9), [e2020WR029261]. https://doi.org/10.1029/2020WR029261

\section{General rights}

Copyright and moral rights for the publications made accessible in the public portal are retained by the authors and/or other copyright owners and it is a condition of accessing publications that users recognise and abide by the legal requirements associated with these rights.

- Users may download and print one copy of any publication from the public portal for the purpose of private study or research.

- You may not further distribute the material or use it for any profit-making activity or commercial gain

- You may freely distribute the URL identifying the publication in the public portal 


\section{Water Resources Research}

\author{
RESEARCH ARTICLE \\ 10.1029/2020WR029261 \\ Key Points: \\ - We use satellite altimetry \\ observations from CryoSat- 2 and \\ a steady-state solver to calibrate \\ hydraulic model parameters \\ - We develop an outlier filtering \\ method for CryoSat-2 observations \\ in ungauged catchments based on \\ rainfall-runoff model simulations \\ - We integrate the altimetry \\ observations in an efficient global \\ calibration approach at low cost \\ compared to a one-dimensional \\ hydrodynamic model
}

Supporting Information:

Supporting Information may be found in the online version of this article.

Correspondence to:

C. M. M. Kittel,

ceki@env.dtu.dk

Citation:

Kittel, C. M. M., Hatchard, S., Neal, J. C., Nielsen, K., Bates, P. D., \& Bauer-Gottwein, P. (2021). Hydraulic model calibration using CryoSat-2 observations in the Zambezi catchment. Water Resources Research, 57, e2020WR029261. https://doi. org/10.1029/2020WR029261

Received 3 DEC 2020

Accepted 30 AUG 2021

\section{Hydraulic Model Calibration Using CryoSat-2 Observations in the Zambezi Catchment}

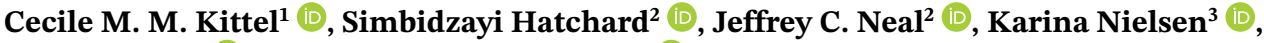 \\ Paul D. Bates ${ }^{2}$ (D), and Peter Bauer-Gottwein ${ }^{1}$ (D) \\ ${ }^{1}$ Department of Environmental Engineering, Technical University of Denmark, Lyngby, Denmark, ${ }^{2}$ School of \\ Geographical Sciences, University of Bristol, Bristol, UK, ${ }^{3}$ National Space Institute, Technical University of Denmark, \\ Lyngby, Denmark
}

\begin{abstract}
Geodetic altimeters provide unique observations of the river surface longitudinal profile due to their long repeat periods and densely spaced ground tracks. This information is valuable for calibrating hydraulic model parameters, and thus, for producing reliable simulations of water level for flood forecasting and river management, particularly in poorly instrumented catchments. In this study, we present an efficient calibration approach for hydraulic models based on a steady-state hydraulic solver and CryoSat-2 observations. In order to ensure that only coherent forcing/observation pairs are considered in the calibration, we first propose an outlier filtering approach for CryoSat-2 observations in data-scarce regions using a simulated runoff produced by a hydrologic model. In the hydraulic calibration, a steady-state solver computes the water surface elevation (WSE) profile along the river for selected discharges corresponding to the days of CryoSat- 2 overpass. In synthetic calibration experiments, the global search algorithm generally recovers the true parameter values in portions of the river where observations are available, illustrating the benefit of dense spatial sampling from geodetic altimetry. The most sensitive parameters are the bed elevations. In calibration experiments with real CryoSat- 2 data, validation performance against both Sentinel-3 WSE and in situ records is similar to previous studies, with Root Mean Square Deviation ranging from 0.43 to 1.14 m against Sentinel-3 and from 0.60 to 0.73 against in situ WSE observations. Performance remains similar when transferring parameters to a onedimensional hydrodynamic model. Because the approach is computationally efficient, model parameters can be inverted at high spatial resolution to fully exploit the information contained in geodetic CryoSat- 2 altimetry.
\end{abstract}

\section{Introduction}

Climate change and human activities have altered river regimes globally, posing significant challenges for water resource managers (Mahé et al., 2013). Flood and drought patterns are changing calling for robust flood hazard and risk assessment. Many river basins are currently ungauged or sparsely gauged (Hannah et al., 2011), as monitoring efforts and data accessibility have severely declined in recent decades (Vörösmarty et al., 2001). However, a reasonable hydraulic representation of river channels is key to producing meaningful large-scale flood models and typically relies on ground monitoring. Simulating river hydraulics at a large scale in poorly instrumented regions requires adapted model structures and simplifications to compensate for constraints on computational resources and insufficient ground observations.

Remote-sensing observations can be used to retrieve hydraulic parameters and have become a key supplement to in situ observations in hydrological studies. Calibration is an important step of hydraulic modeling to ensure that the simulated quantities agree with observations of the system. Very often, bathymetry and channel roughness need to be estimated through calibration or assumptions made by the modeler, for example, regarding channel geometry (Alsdorf et al., 2007). Effective estimation methods in data-poor regions are needed.

Satellite radar altimeters can measure the water surface elevation (WSE) of inland water bodies, which can be used as an alternative to in situ level observations. WSE from satellite radar altimetry has been used increasingly in hydrodynamic model calibration studies as a supplement to in situ gauge data (Paiva et al., 2013; Schneider, Tarpanelli, et al., 2018) or even as a possible surrogate in ungauged basins (Getirana et al., 2013; Jiang et al., 2019; Liu et al., 2015). Dense water level profiles have been proven useful in the 
estimation of distributed hydraulic parameters (F. O'Loughlin et al., 2013; Paris et al., 2016; Schumann et al., 2010). To capture the small-scale variability of river morphology, the spatial sampling must be denser than what can be achieved with short-repeat missions (down to $52 \mathrm{~km}$ at the Equator for the two Sentinel-3 satellites). In that respect, geodetic altimeters such as CryoSat-2 provide the opportunity to extract longitudinal profiles of rivers.

Although not designed for hydrological applications, the benefit of high spatial sampling density of geodetic missions for hydraulic studies has been proven in recent years (Jiang et al., 2019; Schneider, Ridler, et al., 2018; Schneider, Tarpanelli, et al., 2018; Tourian et al., 2016). Schneider, Ridler, et al. (2018) and Schneider, Tarpanelli, et al. (2018) exploited the dense spatial sampling of CryoSat-2 to calibrate channel roughness in the well-gauged Po River at a finer spatial resolution. They compared homogenous roughness parameters to spatially distributed parameters with increasing the spatial resolution from subreach level to 10-km long sections. The Root Mean Square Error (RMSE) against in situ observations improved by up to $29 \mathrm{~cm}$. They showed a strong correlation between the channel sinuosity and the spatially variable calibrated channel roughness. Jiang et al. (2019) showed that missions with high spatial coverage, such as CryoSat-2, improved the RMSE against ground observations by up to $4 \mathrm{~cm}$ compared to missions with wider ground track spacing (i.e., the spacing between satellite tracks) such as Envisat or Jason-2 and -3. Furthermore, the sharpness of the parameter estimates increased with decreasing ground track spacing and increasing spatial detail. Tourian et al. (2016) reached a similar conclusion in a study on spatiotemporal densification of altimetry over rivers. The quality of time series at virtual stations deteriorated slightly when including CryoSat-2 data due to assumptions pertaining to the spatial interpolation. However, CryoSat-2 decreased the bias by increasing the spatial representation of the river profile.

An important step in using satellite altimetry for inland water applications is outlier filtering. Typically, outliers are removed using secondary data sets such as a Digital Elevation Model (DEM) or binary water/ land masks (Jiang et al., 2017; Schneider et al., 2017; Schwatke et al., 2015) or by evaluating the observations themselves, for example, the return waveforms or the backscatter coefficients (e.g., Boergens, Buhl, et al., 2017; Boergens, Nielsen, et al., 2017; Dinardo et al., 2018; Schwatke et al., 2015; X. Zhang et al., 2020). For larger water bodies or short return missions, statistical outlier removal can be used to further refine the filtering (e.g., Nielsen et al., 2015; Schwatke et al., 2015; X. Zhang et al., 2020). For medium-sized rivers, the number of observations per ground track may be too low to perform meaningful statistical outlier removal. When bathymetry is unknown, WSE is dominated by the unknown bed elevation and errors larger than $1 \mathrm{~m}$ may be difficult to detect. This poses a challenge particularly for geodetic missions such as CryoSat-2, where the seasonal signal cannot be removed due to the long revisit time. The dense spatial sampling pattern is impractical for on ground validation and comparison to traditional gauging stations would require the aggregation of observations at the expense of the valuable spatial resolution to obtain time series. Therefore, robust outlier removal procedures are needed to extract useful observations from geodetic altimetry datasets.

Water levels alone can only provide limited information, and the modeling and calibration problems must be adequately formulated to reflect the available observations. Getirana et al. (2013) and Liu et al. (2015) achieve good simulation results when calibrating channel roughness and bed elevation parameters simultaneously in spite of model equifinality. Jiang et al. (2019) investigated the information contained in altimetry WSE and the capability to recover parameter values (bed elevation, channel roughness, and channel geometry) through calibration. Only the bed elevation could be consistently retrieved in combination with one of the other parameters. To avoid ambiguity, channel geometry can be inferred, for example, by assuming rectangular river cross sections (Biancamaria et al., 2009; Jiang et al., 2019) or power channel shapes (Neal et al., 2015) and information from satellite imagery and global databases.

The inverse problem to determine hydrodynamic model parameters is highly nonlinear and non-convex. Studies have used local iterative search algorithms such as Levenberg-Marquardt (Jiang et al., 2019; Schneider, Tarpanelli, et al., 2018) or global search algorithms (Getirana et al., 2013; Liu et al., 2015) to identify the optimal parameters. Global search algorithms are less sensitive to the starting point for non-convex problems; however, a higher number of simulations are usually required to search the parameter space adequately. The computational requirements to calibrate spatially distributed hydraulic parameters increase with the number of estimated parameters. Furthermore, solving the shallow water equations-even with efficient solvers-still requires long simulation time, including warm-up periods (Neal et al., 2012). Using 
a hydrodynamic solver in the inverse problem combined with a global search algorithm is infeasible due to resource requirements. Therefore, efficient calibration approaches balancing parameter accuracy and resource requirements are greatly needed.

In this study, we evaluate the combination of a steady-state solver of the shallow water equations and a global search algorithm for efficient calibration of hydraulic parameters against robustly selected CryoSat-2 observations. Specifically, we

1. Propose an outlier filtering method for CryoSat-2 observations suited for data-scarce regions based on runoff simulations.

2. Evaluate the capability of retrieving spatially distributed parameter values (i.e., channel roughness and bed elevation at least every $20 \mathrm{~km}$ ) using a steady-state solution of the Saint-Venant equations and CryoSat-2 sampling pattern in synthetic calibration experiments.

3. Evaluate the method using real-world CryoSat-2 observations.

4. Assess the performance of the calibrated parameters in dynamic state using a hydrodynamic solver.

The proposed method is most valuable in ungauged catchments, where observations of the targeted calibrated parameters are unavailable. Synthetic experiments allow us to evaluate how the calibration performs and to identify potential limitations (e.g., parameter interactions and behavioral parameters). The full workflow is then assessed for tributaries of the Zambezi, by comparing Sentinel-3 water level and in situ gauge data with the water levels simulated using a 1D hydrodynamic model parameterized with the calibrated parameters.

\section{Study Area}

The Zambezi is located in Southern Africa and is the fourth largest river in Africa. It is 2,574 km long and drains a 1.4 million $\mathrm{km}^{2}$ basin. Precipitation follows a declining North-to-South gradient, with an average of 1,500 $\mathrm{mm}$ in the North and $500 \mathrm{~mm}$ in the South. The wet season is between October and March. Flow is driven largely by precipitation climatology but also by retention in large swamps and floodplains, and artificial reservoirs in the basin.

The Zambezi provides key ecosystem services, supporting large populations of fauna and flora, but is also an important resource for the people living in the basin. We select three regions within the Zambezi as study areas: the Kafue, the Luangwa, and the Upper Zambezi, upstream of the Barotse floodplain, specifically the tributaries Kabompo and Lungwebungo (Figure 1).

\section{Data}

\subsection{Radar Altimetry}

\subsubsection{CryoSat-2}

CryoSat- 2 Level 2 data were provided by the National Space Institute, Technical University of Denmark (DTU Space) for the period July 16, 2010 to March 21, 2018. The data are based on the $20 \mathrm{~Hz}$ Level-1b ESA data set and has been retracked at DTU Space using an empirical retracker based on a sub-waveform threshold (Villadsen et al., 2016). In the Zambezi, CryoSat-2 operates only in Low Resolution Mode (LRM). The DEM and CryoSat-2 observations are reprojected onto the EGM2008 using VDatum (Myers et al., 2007).

\subsubsection{Sentinel-3}

The Sentinel- 3 data set is independent of the data used to calibrate the steady-state model and its virtual stations' monitoring network is denser and with more recent observations than the ground network. Sentinel-3 Level-2 WSE observations were obtained from the ESA GPOD (Grid Processing on Demand SAR Versatile Altimetric Toolkit for Ocean Research and Exploitation) service (available on https://gpod.eo.esa. $\mathrm{int} /$ ). The data have been described and evaluated in Kittel et al. (2021). Performance was quantified in the Upper Zambezi with Root Mean Square Deviation (RMSD) varying between 2.9 and $31.3 \mathrm{~cm}$. In the rest of the river catchment, there was good coherence between historical seasonal trends and the Sentinel-3 water surface elevation. 


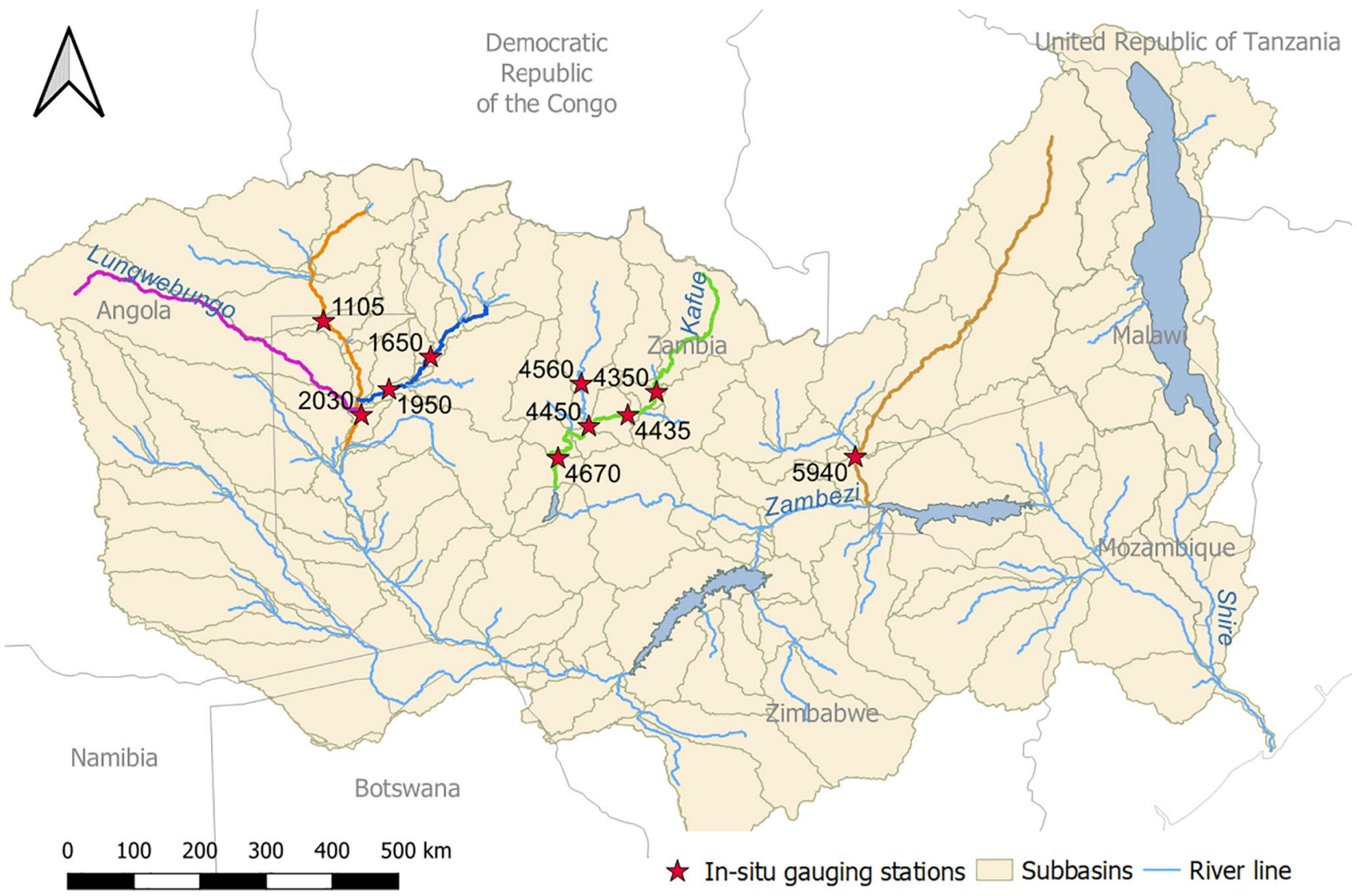

Figure 1. Study area and in situ gauging stations. Calibration is performed for the five highlighted reaches (Lungwebungo, Kabompo, Upper Zambezi, Kafue, and Luangwa).

\subsection{In Situ Observations}

In situ observations were available for five subcatchments in the Upper Zambezi and in the Kafue, and two out of 12 subcatchments in the Luangwa (Table S1 and Figure S1). The Zambezi River Authority (ZRA) kindly provided in situ observations in the Upper Zambezi, completing the data set from Michailovsky and Bauer-Gottwein (2014). In situ discharge was used for the calibration of the rainfall-runoff model, while in situ stage at two stations (Kabompo and Chavuma) was used to validate the hydraulic model. To avoid bias related to the vertical datum of the data sets, all records are referenced to their long-term mean and only amplitudes are compared.

\subsection{Ancillary Datasets}

The river network is delineated using TauDEM v. 5 (Tarboton, 2015) and the Multi-Error-Removed Improved-Terrain Digital Elevation Model (MERIT DEM, Yamakazi et al., 2017). The model is forced using remote sensing observations: Global Precipitation Model (GPM) precipitation (Huffman et al., 2014) and European Centre for Medium range Weather Forecasts-Interim Reanalysis (ECMWF ERA-Interim) (Berrisford et al., 2011) temperature observations for the period 2001 to August 2019. 


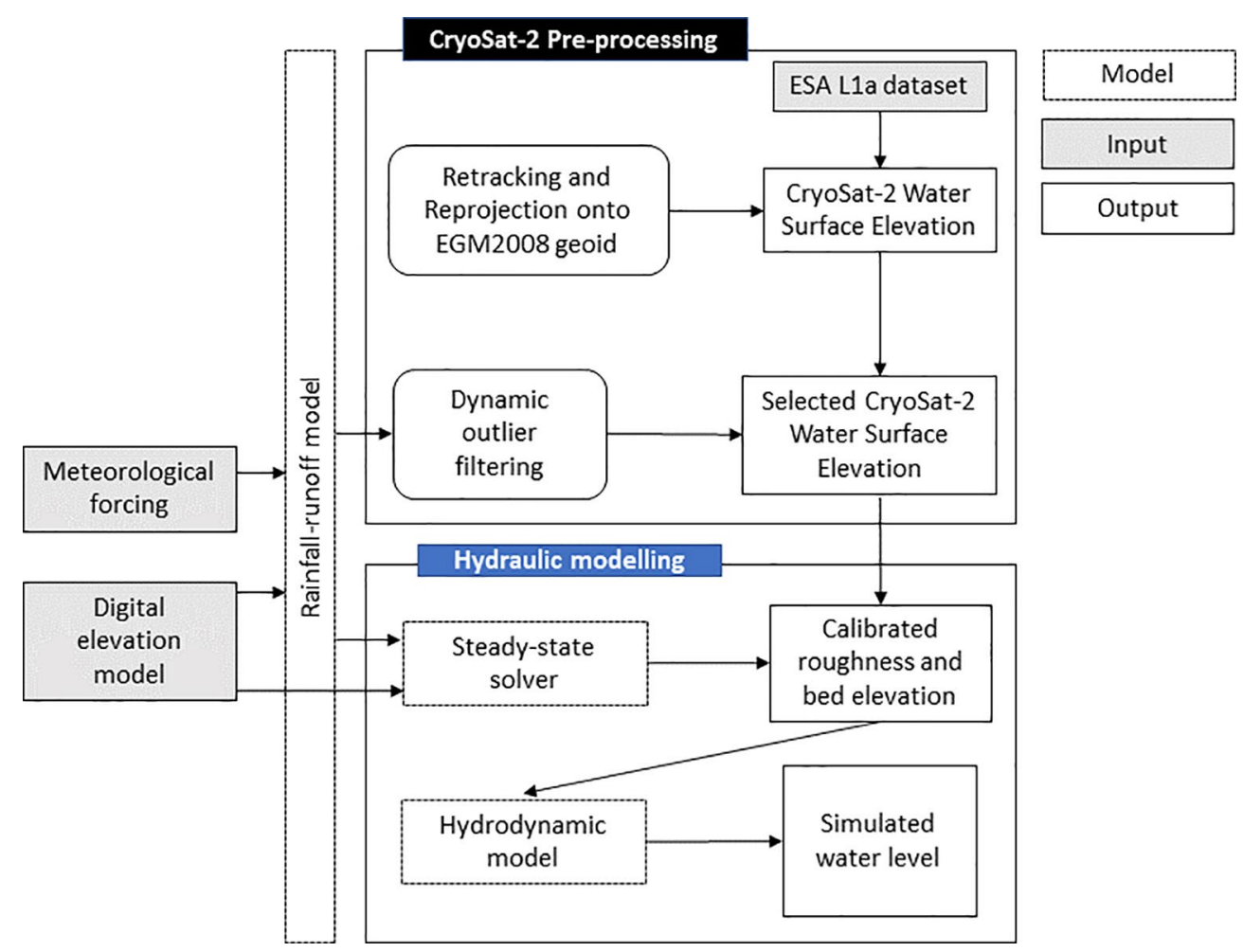

Figure 2. Schematic diagram presenting an overview of the main inputs, models, and outputs of the calibration workflow presented in this study.

\section{Methods}

The entire workflow starting from data selection and ending with hydrodynamic simulation of water levels is shown in Figure 2. The methodology uses remote-sensing inputs and two different models: a rainfall-runoff model and a hydraulic model in steady state and dynamic mode.

\subsection{CryoSat-2 Pre-Processing}

First, we use the water occurrence maps from Pekel et al. (2016) to extract observations over the river. We use a threshold of $10 \%$ water occurrence frequency and allow a 90-m buffer zone around the river mask based on the results from Schneider, Ridler, et al. (2018) and Schneider, Tarpanelli, et al. (2018). The footprint in LRM is several $\mathrm{km}$ wide $\left(2.5 \mathrm{~km}^{2}\right.$ with a diameter of $\left.1.64 \mathrm{~km}\right)$, and a return signal from the water surface can be captured before and after the satellite has crossed the river. Parabolic distortions of the water levels due to this so-called "hooking effect" (Frappart et al., 2006; Maillard et al., 2015) are expected to be negligible at the scale of the buffer applied.

Second, we remove observations deviating from the local value of the MERIT DEM by more than $30 \mathrm{~m}$. This ensures that the surface elevation is indeed within the $60 \mathrm{~m}$ satellite reception window. In total, CryoSat-2 crossed the Zambezi basin 3,724 times during the observation period, resulting in 291,287 observations over water bodies in the basin. Of those, 38,697 observations are over the river network itself. The rejection rate in step one is $10.5 \%$, yielding 34,647 observations after this step.

Unlike previous studies, the third step takes into account the river dynamics by using the output of the rainfall-runoff model. We fit a one-dimensional smoothing spline in the space domain to the CryoSat-2 observations on each river reach. The spline curve is assumed to represent the mean water level for the days of observation. The expected deviation, $\Delta y$, from the mean level, $y_{\text {mean }}$, associated with the simulated discharge, $Q$, at the time of sensing assuming uniform flow and a wide rectangular channel is estimated using Manning's equation for a wide rectangular channel 
Table 1

Assumed Uncertainties of Parameters Used to Estimate the Confidence Interval of the Water Surface Elevation (WSE)

Deviation $\Delta y$

\begin{tabular}{lcc}
\hline Parameter & Estimate & Error propagation \\
\hline Q & Daily discharge from rainfall-runoff model & $\pm 25 \%$ \\
Slope & From univariate spline function (minimum fixed at $10^{-5}$ ) & $2 \times$ standard deviation over the reach \\
Manning's n & 0.035 & Calibration range: $0.02-0.05$ \\
Width & GRWD database & $\pm 25 \%$ \\
\hline
\end{tabular}

$$
Q=\frac{1}{n} \sqrt{S} y^{\frac{5}{3}}
$$

$Q$ is the river discharge $\left(\mathrm{m}^{3} / \mathrm{s}\right), S$ is the bed slope $(\mathrm{m} / \mathrm{m}), n$ is the channel roughness, and $y$ is the channel depth. Equation 1 can be written for the mean discharge and water level and for the specific conditions on the day of CryoSat- 2 overpass. By taking the log-transform and subtracting the two, we can isolate the $\Delta y$

$$
\begin{gathered}
\log (Q)-\log \left(Q_{\text {mean }}\right)=\frac{5}{3}\left(\log (y)-\log \left(y_{\text {mean }}\right)\right) \\
\log (y)-\log \left(y_{\text {mean }}\right)=\log \left(\frac{y_{\text {mean }}+\Delta y}{y_{\text {mean }}}\right)=\frac{3}{5} \log \left(\frac{Q}{Q_{\text {mean }}}\right) \\
\Delta y=\left(\left(\frac{Q}{Q_{\text {mean }}}\right)^{\frac{3}{5}}-1\right) y_{\text {mean }}
\end{gathered}
$$

We calculate the mean discharge, $Q_{\text {mean }}$, using only the days with CryoSat-2 observations. We use error propagation to estimate the total uncertainty of $\Delta y$ based on assumed uncertainties of the discharge estimate, width, slope, and Manning's number (Table 1). The effect of the spline function smoothing factor on the magnitude of the level deviation from the mean is mitigated by using an ensemble of spline curves using varying smoothing factors (0.01-4 times the number of observations in the reach). From the ensemble, we obtain different estimates of the deviation from the mean water level $(\Delta y)$ for each CryoSat-2 observation. If the deviation falls outside of the predicted confidence interval of $\Delta y$ for all smoothing factors, the observation is rejected.

\subsection{Hydraulic Model}

\subsubsection{Steady-State Solver}

The steady-state solver is based on the Saint-Venant equations, which express the mass balance and momentum balance equations for gradually varied one-dimensional flow in an open channel. The equations for the steady-state solver are detailed in Text S1.

Equation 4 is the general form of the equations to solve, when assuming steady flow (i.e., constant discharge over time) and lateral inflow in a rectangular channel, where RHS (Right Hand Side) is the collection of terms not containing the derivative of the depth with respect to the chainage

$$
\begin{aligned}
& \frac{d h}{d x}=\frac{\left(\frac{Q^{2}}{g A^{3}} \frac{\partial A}{\partial x}+S_{0}-\frac{Q^{2}}{K^{2}}+\frac{2 Q \times q}{g A^{2}}\right)}{\left(1-\frac{Q^{2}}{g A^{3}} \frac{\partial A}{\partial h}\right)} \\
& \frac{d h}{d x}=\operatorname{RHS}(x, h(x))
\end{aligned}
$$

where $h$ is the channel depth [m] along the chainage or distance along the channel, $x[\mathrm{~m}], Q$ the discharge $\left[\mathrm{m}^{3} / \mathrm{s}\right], g$ the acceleration due to gravity (set to $9.81 \mathrm{~m}^{2} / \mathrm{s}$ ), $A$ the flow cross-sectional area $\left[\mathrm{m}^{2}\right], q$ the lateral inflow at chainage $x, S_{0}$ the bed slope $[\mathrm{m} / \mathrm{m}]$, and $K$ the conveyance $\left[\mathrm{m}^{3} / \mathrm{s}\right]$. Lateral inflow consists of runoff 
generated by the rainfall-runoff model in tributary subcatchments, which enters the hydrodynamic model at the most upstream node, and runoff produced in the subcatchment itself, which is distributed along the chainage proportionally to the contributing area.

The solver is initialized by calculating the downstream water level boundary condition using Manning's equation and a downstream slope of $2 \mathrm{e}^{-4} \mathrm{~m} / \mathrm{m}$ at chainage, $i$. The downstream slope condition was chosen based on the average slope in the catchment and only affects the most downstream cross section. The level is then calculated stepwise at $\Delta x$ spatial increments, moving upstream along the channel and solving Equation 5 either implicitly (Equation 6) or explicitly (Equation 7):

$$
\begin{gathered}
h_{i-1}=h_{i}-\frac{1}{2} \times\left(\operatorname{RHS}\left(x_{i}, h_{i}\right)+\operatorname{RHS}\left(x_{i-1}, h_{i-1}\right)\right) \times \Delta x \\
h_{i-1}=h_{i}-\operatorname{RHS}\left(x_{i}, h_{i}\right) \times \Delta x
\end{gathered}
$$

The explicit solution is faster but requires smaller steps $\Delta x$ to be stable, while the implicit solution is less sensitive to the spatial increments but requires the solution of a nonlinear implicit equation for $h_{i-1}$ at each time step. We tested the speed of the two solvers using a hypothetical formulation of the Kabompo reach channel. The solutions are virtually identical when solving the equations for steps of less than $500 \mathrm{~m}$. The implicit solver runs in $5.3 \mathrm{~s}$, whereas the explicit solution needs $0.06 \mathrm{~s}$. Even when applying the implicit solution only to cross-sections with observations, the fastest computational time remains slower $(0.17 \mathrm{~s})$, and the large spatial increments affect the final solution. We therefore use the explicit solver using $250 \mathrm{~m}$ spatial steps. If the solution becomes numerically unstable, the spatial step is subdivided into $1 \mathrm{~m}$ increments.

We define calibration cross-sections every $20 \mathrm{~km}$ and at each CryoSat-2 observation. Although the steadystate solver is less computationally demanding than a full hydrodynamic calibration, the number of model parameters must still be constrained. Because of the CryoSat-2 orbit configuration, some observations and thus cross-sections are very closely spaced. This increases the number of calibration parameters and the risk of parameter correlation. We therefore remove cross-sections less than $5 \mathrm{~km}$ apart for shorter reaches (Kabompo and Upper Zambezi) and $10 \mathrm{~km}$ apart for longer reaches (Lungwebungo, Kafue, and Luangwa).

\subsubsection{Hydrodynamic Model}

LISFLOOD-FP is a coupled 1D/2D hydrodynamic model simulating the propagation of flood waves along channels (in 1D) and over floodplains (in 2D). LISFLOOD-FP has three solvers available for calculating channel flow. The kinematic wave routing model only considers the friction slope, assuming that local and convective acceleration terms are negligible and that the free surface gradient is equal to the bed slope. The diffusive wave model includes an additional pressure term. The subgrid channel solves the full shallow water equations with the exception of the convective acceleration term (Neal et al., 2012). All three formulations are numerically stable (De Almeida et al., 2012). The model is specifically designed for poorly gauged catchments and has been implemented for a number of sites, including the Niger River (Neal et al., 2012), the Congo (F. E. O'Loughlin et al., 2020), and rivers in the United Kingdom (Sosa et al., 2020).

We use LISFLOOD-FP to simulate the channel hydrodynamics in the transient state. The model requires information about channel geometry in the form of channel slope, channel width, and bankfull depth from a DEM or surveyed cross section. The bank elevation is derived from the MERIT DEM, the width from the GRWD database, and the bed elevation and channel roughness from the calibrated steady-state solver. The bankfull depth is the difference between the bed and bank elevations. The resolution of the input files is $900 \mathrm{~m}$ instead of the $250 \mathrm{~m}$ used by the steady-state solver to ensure reasonable computation time. The model is forced with daily discharge from headwater catchments and lateral inflow, both simulated by the rainfall-runoff model. Runoff increments are distributed according to the contributing area to each channel pixel, obtained from the river delineation. The model is run in 1D as a means to compare the steady-state solver to a transient solver by burning in the channel bed elevation into the DEM.

\subsection{Hydrologic Model}

The CryoSat-2 pre-processing and the hydraulic model require runoff estimates. In ungauged catchments, these can be obtained using a hydrologic model. In this study, we use a conceptual rainfall-runoff model of 
the Zambezi basin. The rainfall-runoff model is described in Kittel et al. (2018) and is based on the work by L. Zhang et al. (2008) who extended the Budyko framework's concept of limits to monthly and daily time steps. The model builds on a representation of the water balance through demand and supply at various levels. At each time step, Fu's representation of the Budyko curve (L. Zhang et al., 2008) is used to partition precipitation into catchment retention and runoff, and catchment retention into evapotranspiration, groundwater recharge, and root-zone storage. The model is coupled to a Nash cascade of linear reservoirs simulating tributary processes.

The model is calibrated against in situ discharge records from 1990-present after careful analysis to ensure hydrometeorological stationarity can be assumed between the observation and simulation periods. In order to parametrize ungauged subcatchments, we use the same catchment characteristics as proposed in Kittel et al. (2020): the subcatchments were grouped into calibration clusters using the European Space Agency Climate Change Initiative Land Cover map v.2 (ESA, 2017) and the MERIT DEM and calibrated holistically using an aggregated objective function at catchment scale allowing trade-offs between parameters in nested subcatchments. The regionalization and resulting calibration zones are summarized in Table S2. Performance was then evaluated based on the flow duration curves using equal flow volume classes as described in Westerberg et al. (2011) and on the daily discharge climatology RMSD. Additionally, we use the Kling-Gupta Efficiency to quantify post-calibration performance (Gupta et al., 2009). The model setup and performance are summarized in Tables S1 and S2.

\subsection{Hydraulic Model Calibration}

\subsubsection{Global Search Algorithm and Performance Statistics}

The bed elevation and channel roughness are calibrated for each cross section using the Shuffled Complex Evolution algorithm from the University of Arizona (SCEUA) developed by Duan et al., (1992) and implemented in Python using SPOTPY (Houska et al., 2015). The algorithm uses "complexes" to sample the parameter space. The complexes are groups of parameter samples, which are evolved independently and shuffled after each evolution cycle to ensure an efficient global search. The bed elevation parameters are initialized using a spline function interpolating between the CryoSat-2 WSE observations minus one meter to adjust for the water level. The bed elevation can vary between -5 and $3 \mathrm{~m}$ from this initial value. The channel roughness is initialized at 0.04 and allowed to vary between 0.018 and 0.055 . The calibration objective function consists of a data misfit term comparing the residuals between the CryoSat-2 WSE and the simulated WSE

$$
E_{i}=\left(w_{i}+z_{i}\right)-\mathrm{WSE}_{C 2, i}
$$

and a smoothness preference for the two parameters along the chainage

$$
S m_{i}=\frac{\sqrt{\left(p_{i}-p_{i-1}\right)^{2}}}{f_{\text {smooth }}}
$$

$f_{\text {smooth }}$ is the smoothness preference: smaller values will give higher weight to $\mathrm{Sm}$ and force the solver to move toward a smoother solution with less abrupt changes in bed elevation or channel roughness, represented by $p$ in Equation 9. The calibration objective is

$$
\text { Obj }=\sqrt{\frac{1}{2 N}\left(\sum_{i=1}^{N} E_{i}^{2}+\sum_{i=1}^{N} S m_{i}^{2}\right)}
$$

The smoothness preference must be chosen to balance a realistic water surface and allowing features from the bed and channel roughness to be simulated. The preference is set to 1, giving equal weight to the smoothness and error objectives due to the types of parameters evaluated. Thus, the difference in magnitude between the objectives are balanced while still prioritizing a good fit between data and observation.

We compute three additional diagnostic performance measures to evaluate the post-calibration performance of the hydraulic model: the Pearson correlation coefficient, Spearman's rank correlation coefficient, and the non-parametric Kling-Gupta Efficiency (Pool et al., 2018). The Kling-Gupta Efficiency (KGE) combines the 
Pearson correlation coefficient and the biases between mean and observed mean discharge and between the simulated and observed standard deviation. In the non-parametric version, the rank correlation is used instead, and the discharge variability performance is computed using the flow duration curve. This method is less sensitive to assumptions of data linearity, data normality, and outliers (Pool et al., 2018).

\subsubsection{Synthetic Experiments}

Synthetic calibration experiments are used to evaluate the capabilities of the steady-state solver and calibration algorithm to retrieve the bed elevation and channel roughness using CryoSat-2-type observations of WSE. We generate a synthetic set of parameters (i.e., bed elevation and Manning's $\mathrm{n}$ at all cross sections) to produce synthetic CryoSat-2 observations in the Kabompo reach, that is, a synthetic representation of the true WSE. To reflect data uncertainties, the synthetic truth is perturbed with normally distributed random noise with varying standard deviations. The resulting three experiments are:

1. Three-centimeter standard deviation representing in situ water level accuracy.

2. Twenty-centimeter standard deviation representing high accuracy for altimetry WSE.

3. Forty-centimeter standard deviation representing average accuracy for altimetry WSE.

Parameter sensitivity is evaluated by conducting an extended Fourier amplitude sensitivity test (FAST) (Saltelli et al., 1999) as implemented in SPOTPY (Houska et al., 2015). We compare the total sensitivity of the bed elevation and channel roughness at each cross-section to assess the spatial sensitivity of the two parameters along the river chainage. Over 686.000 model runs are performed to achieve the recommended sampling of the parameter space based on the number of calibration parameters in the synthetic example (Houska et al., 2015; Saltelli et al., 1999).

\subsubsection{Calibration Against Real-World Observations}

We then use the real-world CryoSat-2 observations and calibrate the bed elevation and channel roughness in five reaches in the Zambezi catchment. To ensure that the steady-state assumption is reasonable, we choose CryoSat-2 observations where the 10-day discharge gradient is less than 5\% of the mean discharge. This is the case for $69.9 \%$ of the CryoSat-2 observations. To minimize the impact of uncertainties related to the CryoSat-2 observations and runoff simulations, we classify the simulated runoff and CryoSat-2 observations into discharge classes based on the runoff histogram and time of observation. The steady-state model is run for each class and residuals are calculated for all CryoSat-2 observations within the class.

\section{Results}

\subsection{CryoSat-2 Outliers Filtering}

Figure 3 illustrates the CryoSat-2 river longitudinal profiles and outlier filtering for each of the five reaches. In the downstream part of the Upper Zambezi, water level increases of $5 \mathrm{~m}$ are unlikely during the low-flow season; therefore, the associated CryoSat-2 observations are rejected. However, a similar increase may occur during the high-flow season, highlighting the benefit of a dynamic threshold. The rejection rate is between $10 \%$ for Lungwebungo and $24 \%$ for Luangwa.

The main challenges in terms of outlier filtering are adequately fitting the spline function, so it is representative of the mean water surface profile along the river line. In the Upper Zambezi, Kafue, and Kabompo, we removed observations deviating from the spline function by more than twice the residual standard deviation and fitted a new spline function through the remaining observations, resulting in rejection rates of $18 \%, 19 \%$, and 23\%, respectively. This was necessary due to the combination of large variations in WSE and changes in the reach slope. There is a fine balance between overfitting outliers and smoothing the mean water level.

The Luangwa River runs from North-East to South-West. CryoSat-2 predominantly crosses the Luangwa between March and end of November, thus missing the wet season. Therefore, the CryoSat-2 observations are expected to be relatively close to the mean water elevation with very small predicted residuals. In this case, the outlier filtering is particularly sensitive to the estimation of the mean water surface profile. However, reducing the smoothing factors of the spline curve ensemble also increased the risk of admitting clear outliers. 


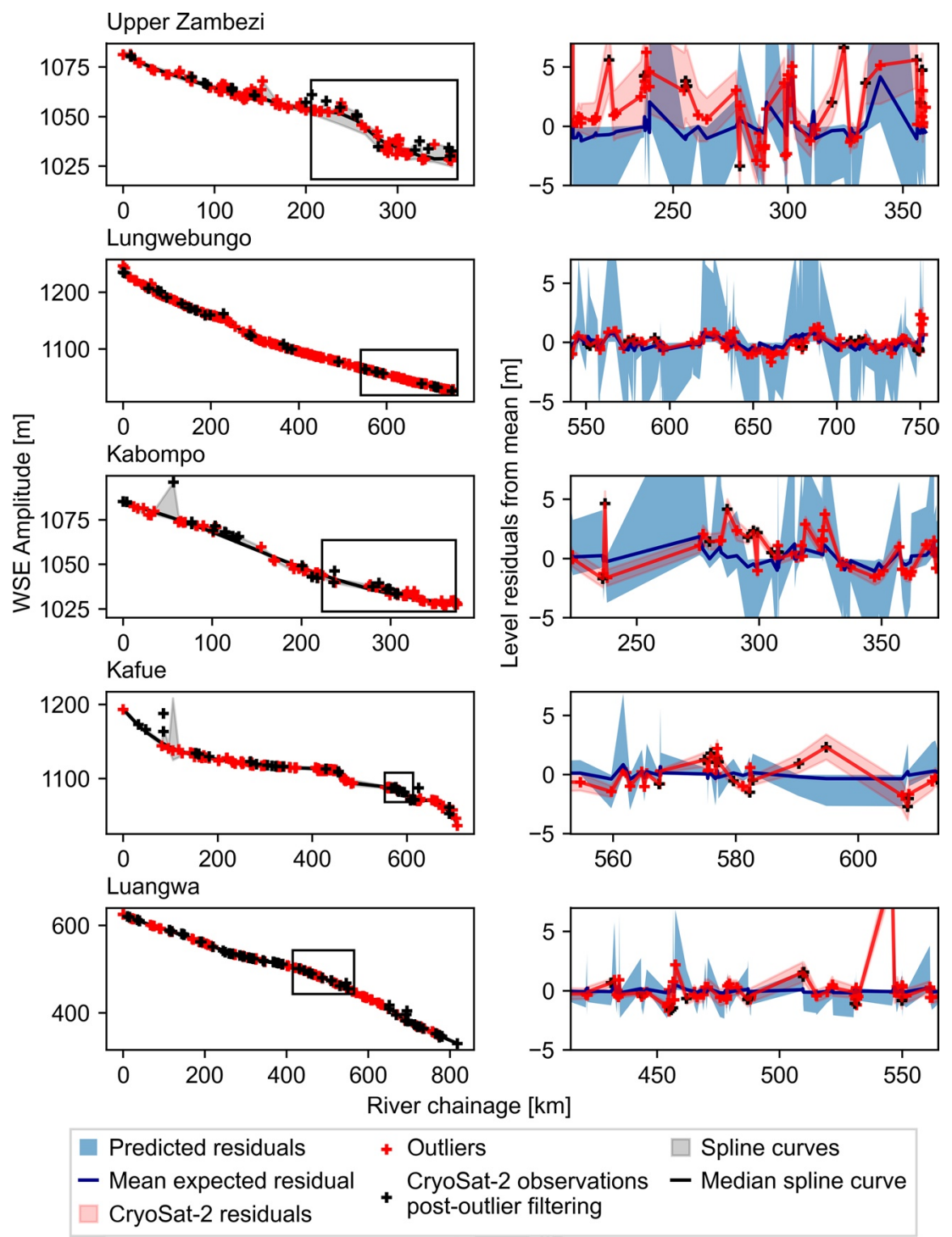

Figure 3. Selection of CryoSat-2 observations in the Zambezi. Left: the longitudinal profile of each studied river reach and right: the illustration of the outlier filtering process for a subset of each reach.

\subsection{Synthetic Test}

The synthetic tests evaluate the impact of observation uncertainties by using respectively 3,20 , and $40 \mathrm{~cm}$ standard deviations to perturb the synthetic CryoSat-2 observations. The results are shown in Figure 4.

A difference in performance is seen when increasing the observation uncertainty, as seen in the performance statistics (Table 2) and the spread in the scatter plot in Figure 4. The RMSD is in the order of magnitude of the observation uncertainty. For all assumed uncertainty levels, parameter retrieval is most improved at cross sections with synthetic observations. This was expected and confirms the advantage of using spatially dense observations to calibrate hydrodynamic parameters. The weighted objective used in calibration includes a smoothness factor. There is good consistency between the RMSD and calibration objective, with the smoothness factor forcing a reduction in variations where the observation density is low.

The downstream sections are most sensitive during calibration according to the FAST sensitivity analysis. The Saint-Venant equations account for backwater effects; therefore, changes in downstream parametrization have an impact on all upstream evaluation points. Tweaking upstream parameters will mainly impact the upstream predictions in the steady-state solver and thus have limited effect on the overall performance. 

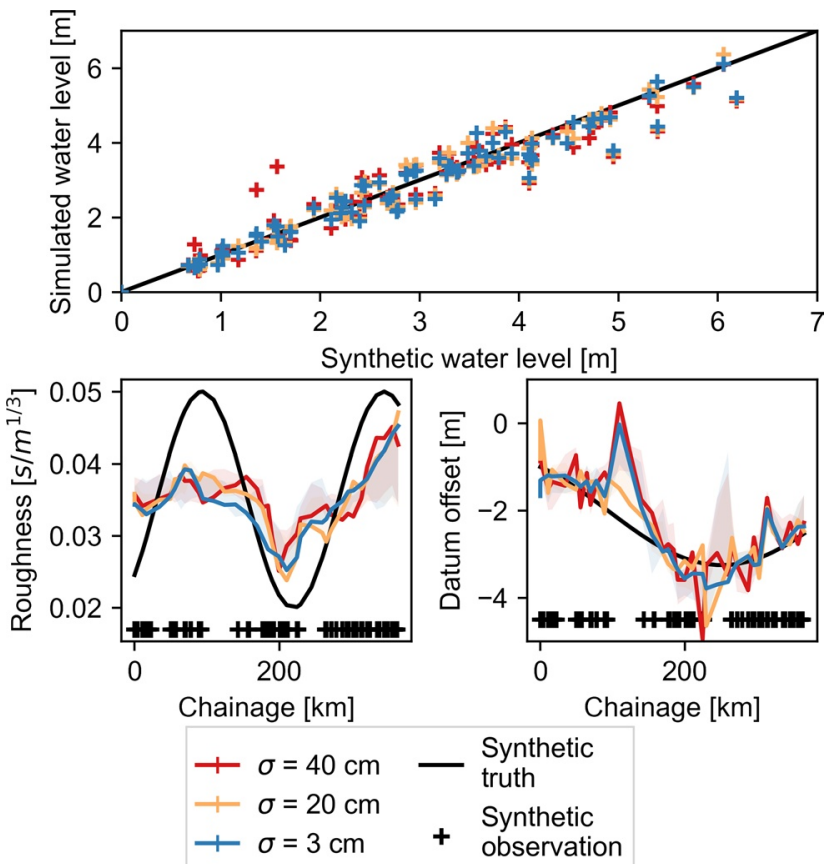

Figure 4. Top: Simulated against synthetic water level (the calibrated bed elevation is subtracted) for the three experiments. Bottom: Retrieval of synthetic Manning's roughness, $n$ (left) and offset from the initial datum guess (right) by the model. The black crosses indicate the chainage of the synthetic observations consistent with the CryoSat-2 observation density.
Sensitivity is driven by the observation density, as seen for the parameters at cross-section 12, which correspond to the first large gap in observations and are not sensitive at all (Figures 4 and 5).

The analysis also confirms that the objective function is less sensitive to the channel roughness, $n$, than the datum offset, $z$, as shown in Figure 5 (top). The scatter plots in Figure 5 provide information on whether tradeoffs during calibration can explain the low sensitivity of the channel roughness. We plot the results of the low uncertainty calibration, to remove the effect of observation uncertainty on parameter retrieval. During calibration, the parameters converge to relatively narrow parameter spaces. The synthetic truth is not always within the optimum range, which is due to the global objective function and trade-offs between parameters at the different cross-sections.

The bed elevation and channel roughness have similar local effects: overestimating the channel roughness raises the water level but can be compensated by slightly decreasing the bed elevation locally. Previous studies have shown that the two parameters impact the water surface differently over different characteristic spatial scales (Durand et al., 2014; Wood et al., 2016). When calibrating a single, global roughness parameter, the bed elevation will tend to have a local impact, whereas adjustments of the friction parameter will have a more diffuse effect and impact a longer portion of the reach. Thus, the two parameters can be retrieved simultaneously. In this study, both parameters are calibrated locally and both have a local impact. This can be seen at cross-section 0 , where the best performing parameter samples (objective function less than 0.2) form a straight line toward the synthetic truth. Thus, although parameters can be retrieved successfully at some cross-sections, there is still model ambiguity (e.g., at cross-section 4 ). The ambiguity can be partially resolved by increasing the observation density.

\subsection{Calibration Using Real-World CryoSat-2 Observations in the Zambezi}

Figure 6 shows the calibrated longitudinal water surface profiles at the five locations in the Zambezi after calibrating the steady-state solver against real-world CryoSat-2 observations. Overall, the simulated WSE corresponds quite well to the CryoSat-2 observations.

LISFLOOD-FP models are run for each reach using the calibrated channel roughness and bed elevation. Table 3 summarizes performance statistics of the calibration and evaluation based on the steady-state solver and the transient solution, respectively. We compare the simulated and observed water level by subtracting calibrated bed elevation from the satellite altimetry WSE. This removes the otherwise dominating effect of elevation on the performance. Overall performance is good and consistent across performance metrics.

Table 2

Calibration Performance for the Synthetic Experiments at All Cross-Sections and at Cross-Sections With Synthetic Observations (Gauged Cross-Sections)

\begin{tabular}{lccc}
\hline Observation uncertainty & $\sigma=40 \mathrm{~cm}$ & $\sigma=20 \mathrm{~cm}$ & $\sigma=3 \mathrm{~cm}$ \\
\hline WSE objective & 0.26 & 0.15 & 0.09 \\
RMSD [m] & 0.33 & 0.17 & 0.08 \\
Datum offset RMSD [m] & 0.75 & 0.49 & 0.56 \\
Considering only gauged & 0.53 & 0.39 & 0.39 \\
$\quad$ cross-section & & & 0.0072 \\
Manning's n RMSD [s/m & 0.0083 & 0.0075 \\
\hline
\end{tabular}

Note. RMSD, Root Mean Square Deviation. 

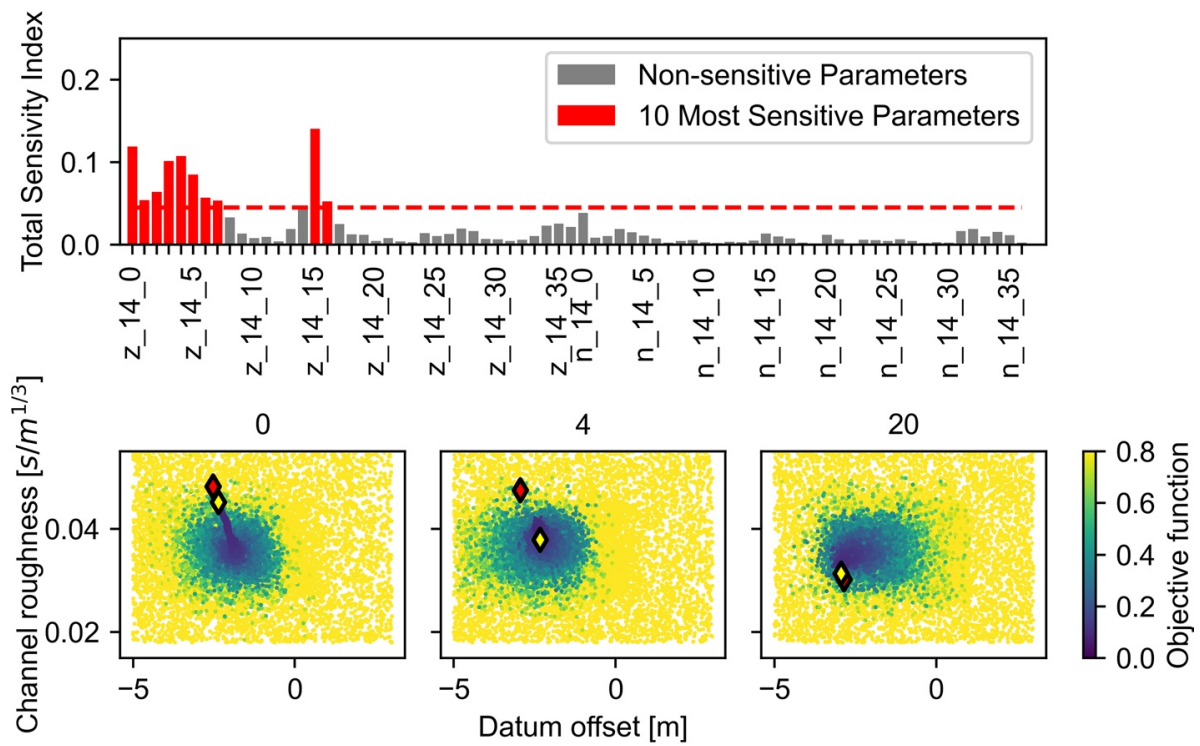

Synthetic truth $\diamond$ Calibrated parameter

Figure 5. Top: FAST sensitivity analysis of the synthetic calibration test with $20 \mathrm{~cm}$ standard deviation; the parameters are numbered from downstream to upstream cross-sections. Bottom: Sampling pattern and model performance during calibration at three randomly selected cross-sections. Cross-section numbering is from downstream to upstream. The objective is lowered during calibration.
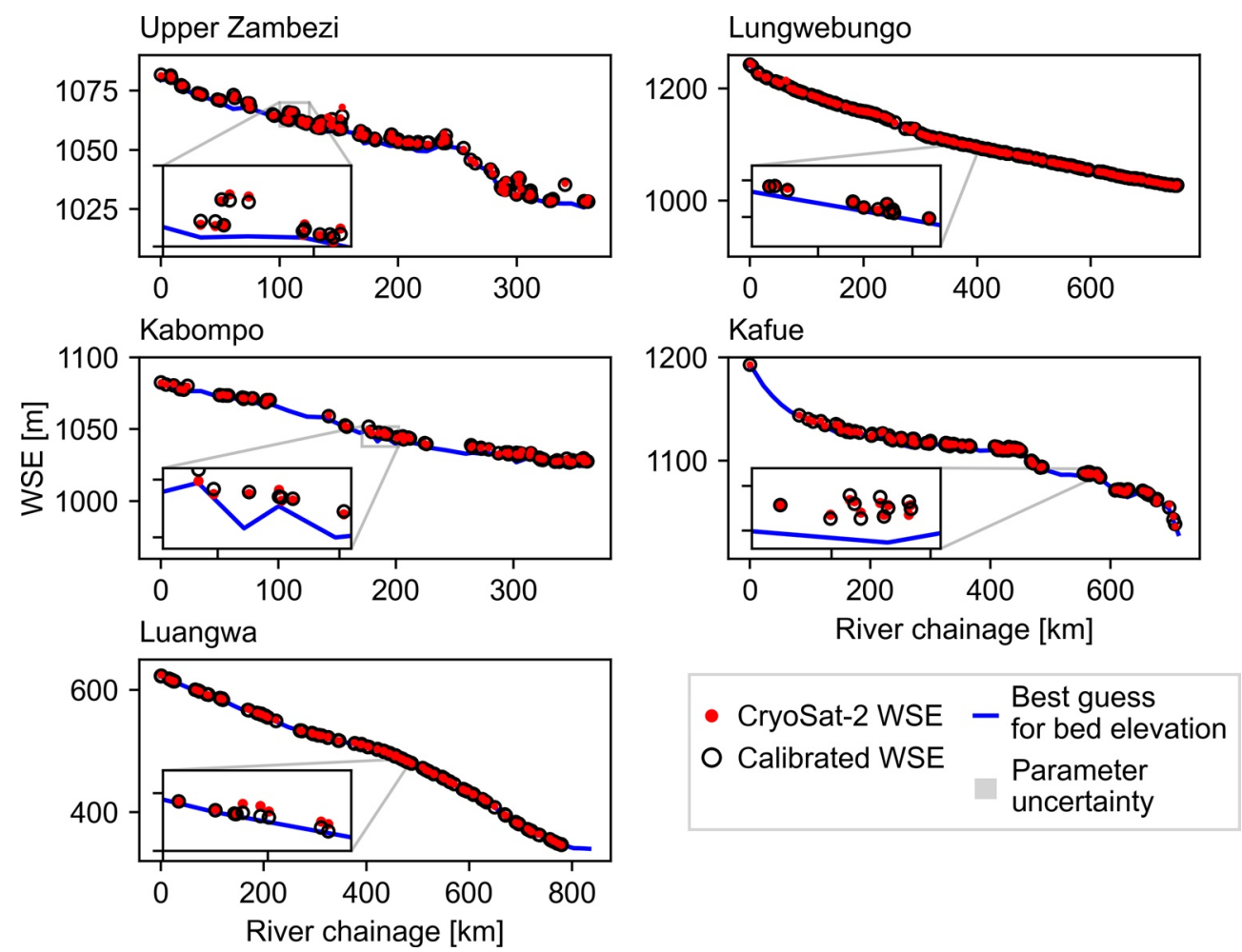

Figure 6. Calibrated longitudinal profile of the bed elevation and the water surface elevation (WSE) simulated by the steady-state solver for the five subreaches in the Zambezi-the calibrated WSE is computed using the discharge of the corresponding day of observation by CryoSat-2 assuming steady state. 


\section{Table 3}

Steady-State (SS) Solver and LISFLOOD-FP (L) Performance Statistics Using Calibrated Parametrization and CryoSat-2 Observations (C2), Sentinel-3 (S3) Water Surface Elevation (WSE), and In Situ Water Level Observations

\begin{tabular}{|c|c|c|c|c|c|c|c|c|c|c|c|c|c|c|}
\hline \multirow{3}{*}{$\begin{array}{l}\text { Data source } \\
\text { Solver }\end{array}$} & \multirow{3}{*}{$\frac{\frac{\text { Weighted objective }}{\mathrm{C} 2}}{\mathrm{SS}}$} & \multicolumn{5}{|c|}{ RMSD } & \multicolumn{2}{|c|}{ Non-parametric KGE } & \multicolumn{3}{|c|}{ Pearson $r^{2}$} & \multicolumn{3}{|c|}{ Spearman $r^{2}$} \\
\hline & & \multirow[b]{2}{*}{ SS versus $L$} & \multicolumn{2}{|c|}{$\mathrm{C} 2$} & \multirow{2}{*}{$\frac{\mathrm{S} 3}{\mathrm{~L}}$} & \multirow{2}{*}{$\frac{\text { In situ }}{\mathrm{L}}$} & \multirow{2}{*}{$\begin{array}{c}\mathrm{C} 2 \\
\mathrm{~L}\end{array}$} & \multirow{2}{*}{$\frac{\text { In situ }}{\text { L }}$} & \multirow{2}{*}{$\frac{\mathrm{C} 2}{\mathrm{~L}}$} & \multirow{2}{*}{$\frac{\mathrm{S} 3}{\mathrm{~L}}$} & \multirow{2}{*}{$\frac{\text { In situ }}{\mathrm{L}}$} & \multirow{2}{*}{$\frac{\mathrm{C} 2}{\mathrm{~L}}$} & \multirow{2}{*}{$\frac{\mathrm{S} 3}{\mathrm{~L}}$} & \multirow{2}{*}{$\frac{\text { In situ }}{\mathrm{L}}$} \\
\hline & & & SS & $\mathrm{L}$ & & & & & & & & & & \\
\hline Upper Zambezi & 0.68 & 0.39 & 0.83 & 0.79 & 0.71 & 0.73 & 0.79 & 0.25 & 0.91 & 0.79 & 0.84 & 0.79 & 0.82 & 0.92 \\
\hline Lungwebungo & 0.78 & 0.98 & 0.88 & 1.31 & 0.43 & & 0.50 & & 0.37 & 0.58 & & 0.53 & 0.58 & \\
\hline Kabompo & 0.45 & 0.32 & 0.61 & 0.71 & 1.14 & 0.60 & 0.89 & 0.49 & 0.90 & 0.69 & 0.90 & 0.90 & 0.79 & 0.90 \\
\hline Kafue & 0.74 & 0.35 & 0.89 & 1.05 & 0.62 & & 0.78 & & 0.85 & 0.91 & & 0.85 & 0.90 & \\
\hline Luangwa & 0.54 & 0.17 & 0.66 & 0.60 & 0.99 & & 0.11 & & 0.58 & 0.43 & & 0.44 & 0.61 & \\
\hline
\end{tabular}

Note. The Pearson and Spearman correlation coefficients are calculated by subtracting the calibrated bed elevation from the CryoSat-2 observations to remove the effect of elevation on the performance. A p-value below $2.5 \%$ is considered significant-in all cases the p-value is below the threshold and the correlation is significant.

KGE, Kling-Gupta Efficiency; RMSD, Root Mean Square Deviation.

The weighted objective includes a smoothness and shallowness preference and is therefore generally larger than the RMSD. There is a good correlation between the simulated WSE and CryoSat- 2 WSE. The RMSD is between 0.58 and $0.88 \mathrm{~m}$.

Figure 7 shows the WSE time series simulated by LISFLOOD-FP against the in situ records at Chavuma and Watopa and against the Sentinel-3 WSE. We note that there are some timing issues in the water level prediction, particularly at Chavuma, and in the low-flow predictions at Watopa. These are consistent with uncertainties in the rainfall-runoff model, which forces the steady-state hydraulic model and hydrodynamic
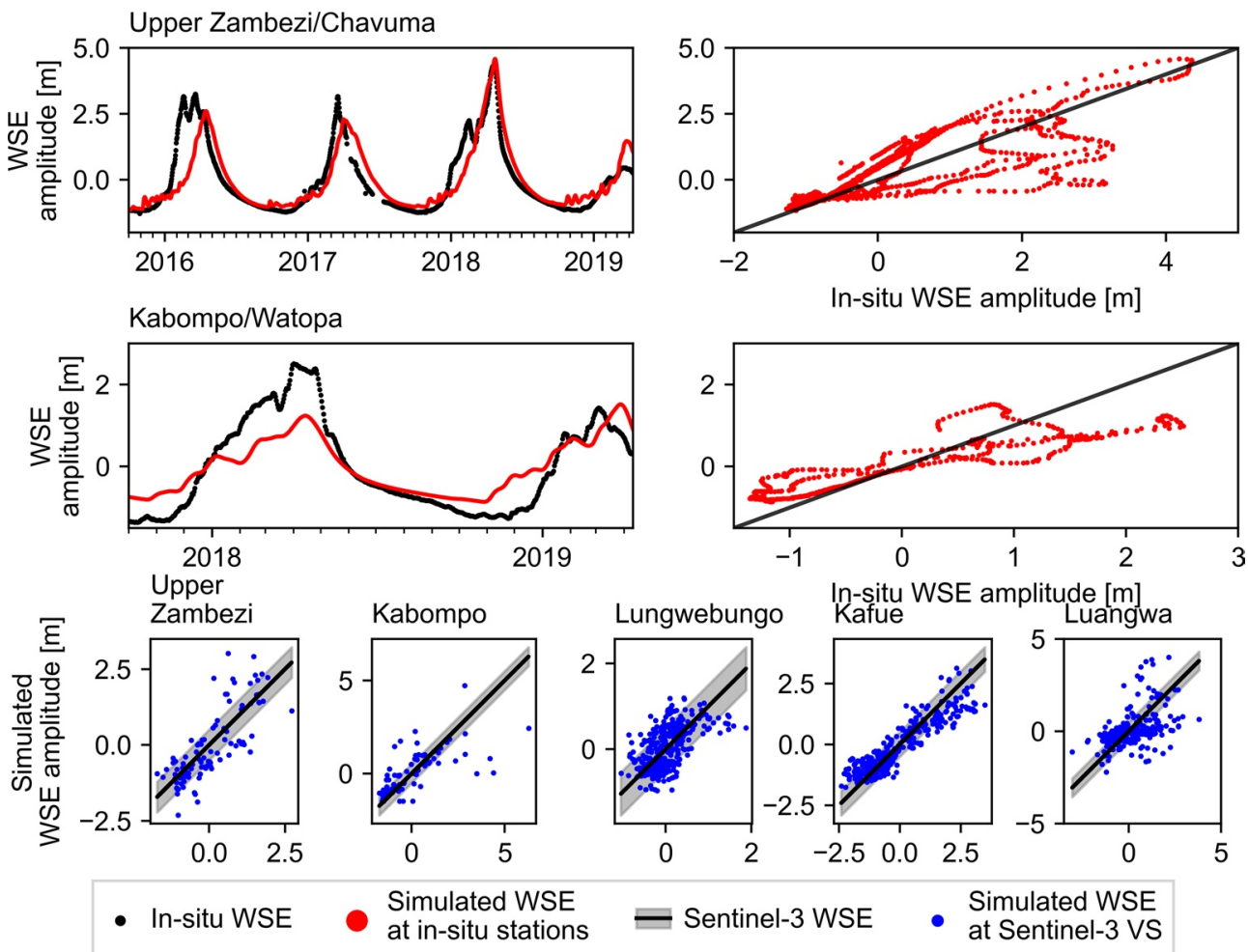

Figure 7. Dynamic water surface elevation (WSE) at in situ stations Chavuma (Upper Zambezi-top row) and Watopa (Kabompo-middle row) and simulated by LISFLOOD-FP and Sentinel-3 WSE versus simulated WSE by LISFLOODFP at Sentinel-3 VS (bottom row). The shaded area represents the expected uncertainty of Sentinel-3 of up to $50 \mathrm{~cm}$. 
models. Sentinel-3 is a SAR altimeter and expected to have a lower uncertainty than a conventional altimeter (3-30 cm in the Zambezi, according to Kittel et al., 2021). We represent the Sentinel-3 data with a slightly higher uncertainty, as the stations used in this study could not all be evaluated against in situ observations. A conservative upper bound of $50 \mathrm{~cm}$, consistent with previous studies on altimetry observations of inland water (Villadsen et al., 2016) was therefore selected to indicate the Sentinel-3 uncertainty in Figure 7.

The steady-state and transient solutions differ by around 20-40 cm in RMSD against CryoSat-2 observations, which is in the order of magnitude of the expected CryoSat-2 uncertainty in LRM (Villadsen et al., 2016). The difference between the steady-state and transient solution $(22-98 \mathrm{~cm}$ ) can be partly explained by (a) the difference between the subgrid representation of the channel and the 1-dimensional line representation of the steady-state solver and (b) the coarser spatial resolution (900 m instead of $250 \mathrm{~m}$ ) needed to allow reasonable computation time. The performance metrics remain comparable or better than results reported in previous studies.

Overall, the performance is consistent with previous studies with RMSD values between 0.60 and $1.31 \mathrm{~m}$. Jiang et al. (2019) obtained RMSD between the simulated and altimetry WSE between 0.72 and $1.6 \mathrm{~m}$, when using various combinations of altimetry data sets, with CryoSat-2 alone giving a calibration performance of $1.28 \mathrm{~m}$. Domeneghetti et al. (2014) obtained a RMSD of around $1 \mathrm{~m}$ using Envisat data to calibrate a hydrodynamic model of the Po River. F. E. O'Loughlin et al. (2020) achieved RMSD between 0.84 and $2.02 \mathrm{~m}$ in the Congo when comparing a large-scale hydraulic model forced with in situ and simulated discharge. As in this study, the channel depths and friction were calibrated against satellite altimetry WSE observations; however, the study used a global channel friction parameter.

\section{Discussion}

\subsection{CryoSat-2 Data Selection}

The CryoSat-2 observations used in the calibration must be accurate and representative of the river WSE. CryoSat-2 is not error-free and is difficult to validate due to the high spatial sampling but low temporal sampling frequency. In this study, we used hydrological simulations from a calibrated hydrological model to assess the validity of the CryoSat-2 observations. Instead of selecting a fixed threshold to assess the deviation of a given CryoSat-2 observation from the local river surface longitudinal profile, we predict the expected range of water level deviation based on the hydrological conditions in the reach at the time of observation.

Robust outlier removal is essential but highly challenging in poorly instrumented catchments. By exploiting simulations of discharge, which are already available as input to the hydraulic model, a more refined method was developed in this study. Valid observations may be rejected due to errors in the corresponding simulated discharge. This is likely to occur in poorly gauged catchments, where calibration is constrained by data availability. Retaining these observations may introduce errors in the calibration, as it fits the parameters to produce water levels, which are unlikely to have occurred under the simulated flow conditions. In this study, we demonstrate the method in a sparsely gauged catchment, where the added value of altimetry WSE is high. In future studies, we recommend applying this method in a highly instrumented catchment to validate the proposed method.

\subsection{Model Performance}

The steady-state assumption of the solver is a simplification of the actual hydrodynamic conditions; it can be run for specific time steps corresponding to satellite overpasses greatly reducing computational time. The results are in the order of magnitude of the calibration data uncertainty and comparable to previous studies. This confirms that the method can be used to calibrate hydraulic models efficiently against spatially dense WSE observations.

Furthermore, simplifications are necessary to represent poorly instrumented river channels for hydraulic modeling. In particular, some assumption on the cross-section geometry is required (e.g., trapezoidal, rectangular channel, and power channel). In this study, we select a simple rectangular shape and use global river width databases to obtain the missing information about the mean width. An alternative approach 
could be to use a power law to correlate the area and water depth and the conveyance and water depth, removing the need for an explicit definition of the channel shape.

Neal et al. (2015) investigated incorporating the channel cross-section uncertainty into large-scale flood inundation models of data sparse areas and showed that performance improved in models with calibrated channel friction and rectangular channels. Their results suggest that a channel shape parameter, roughness and elevation could be fitted simultaneously, provided sufficient dynamic observations are available in the reach. Neal et al. (2015) also showed that informing the model with even basic information about the channel geomorphology, such as width-discharge curves from optical or radar satellite imagery improved model calibration against level observations. The shape and friction have similar effects locally and calibrating the shape parameter may be more appropriate than calibrating friction for narrow channels, where the assumption of a rectangular shape is less appropriate.

The calibration of local variations in channel roughness greatly increases the parameter space and poses a further challenge. Jiang et al. (2019) demonstrated that altimetry alone is insufficient to calibrate geometry parameters as well as spatially distributed channel roughness. The reason for this is clear: local channel conveyance depends on both the channel roughness and flow area. Thus, there is model ambiguity and additional data sets are required to constrain the increased parameter space (e.g., channel width under known flow conditions). The unknown channel bed elevation prevents a satisfactory calibration of the level to area relationship and channel roughness. Thus, an interesting future path could include exploring whether the geometry parameters could be sufficiently constrained from alternative or new remote sensing observations, or whether calibrating local changes in channel geometry may be more robust than calibrating the channel roughness.

\subsection{D Versus 2D Hydrodynamic Model}

The steady-state solver is one-dimensional and thus does not include bank overflow and floodplain processes. This will introduce errors in shallow reaches during extreme events, where the peak water level might be overpredicted to accommodate the high flow in a rectangular channel. Therefore, we only consider tributary branches of the Zambezi. The subgrid solver in LISFLOOD-FP calculates the floodplain water level when the level in the channel exceeds the bank elevation. This requires a robust match between bed and bank elevation. Figure 8 illustrates the calibrated cross-sections versus the DEM at selected locations of the five reaches. Because the steady-state solver only calibrates the bed elevation, the bank elevation is extracted from the DEM. This poses a challenge if the calibrated bed is equal to or higher than the DEM elevation height, for example, in the Upper Zambezi (Figure 8). The calibration information then becomes obsolete. If the difference is too small, the channel might overflow too often (as might be the case at Kabompo). Thus to apply the results in a $2 \mathrm{D}$ modeling setup, the bank elevation must be corrected to ensure the channel is correctly burned into the floodplain, for example, using SAR imagery to deduce the bank and bed elevation relationship (Wood et al., 2016). Despite the higher demands for parametrization and computation power, a two-dimensional solver would be necessary to adequately model the entire Zambezi, particularly the delta, which is not included in this study. The proposed method may, however, still be a useful stepping-stone for more complex modeling efforts, particularly in poorly instrumented catchments.

The DEM will usually give the elevation of the water surface in the channel at the time of observation. This means that the calibrated bed elevation is more likely to be below than above the DEM elevation. The opposite occurs at Chavuma, where the slope is very high. CryoSat-2 observations before and after the drop in elevation force a compromise.

\section{Conclusion}

A reasonable hydraulic representation of river channels for large-scale flood modeling is essential but challenging to obtain in data poor regions. In this study, we propose using a steady-state solver to calibrate hydraulic parameters against geodetic altimetry observations. We propose an informed outlier rejection framework based on simulated discharge to select CryoSat-2 observations for calibration. The approach successfully removes obvious outliers, while allowing reasonably large deviations from the estimated mean level, provided there is coherence with the hydrological conditions on the day of observation. Furthermore, 

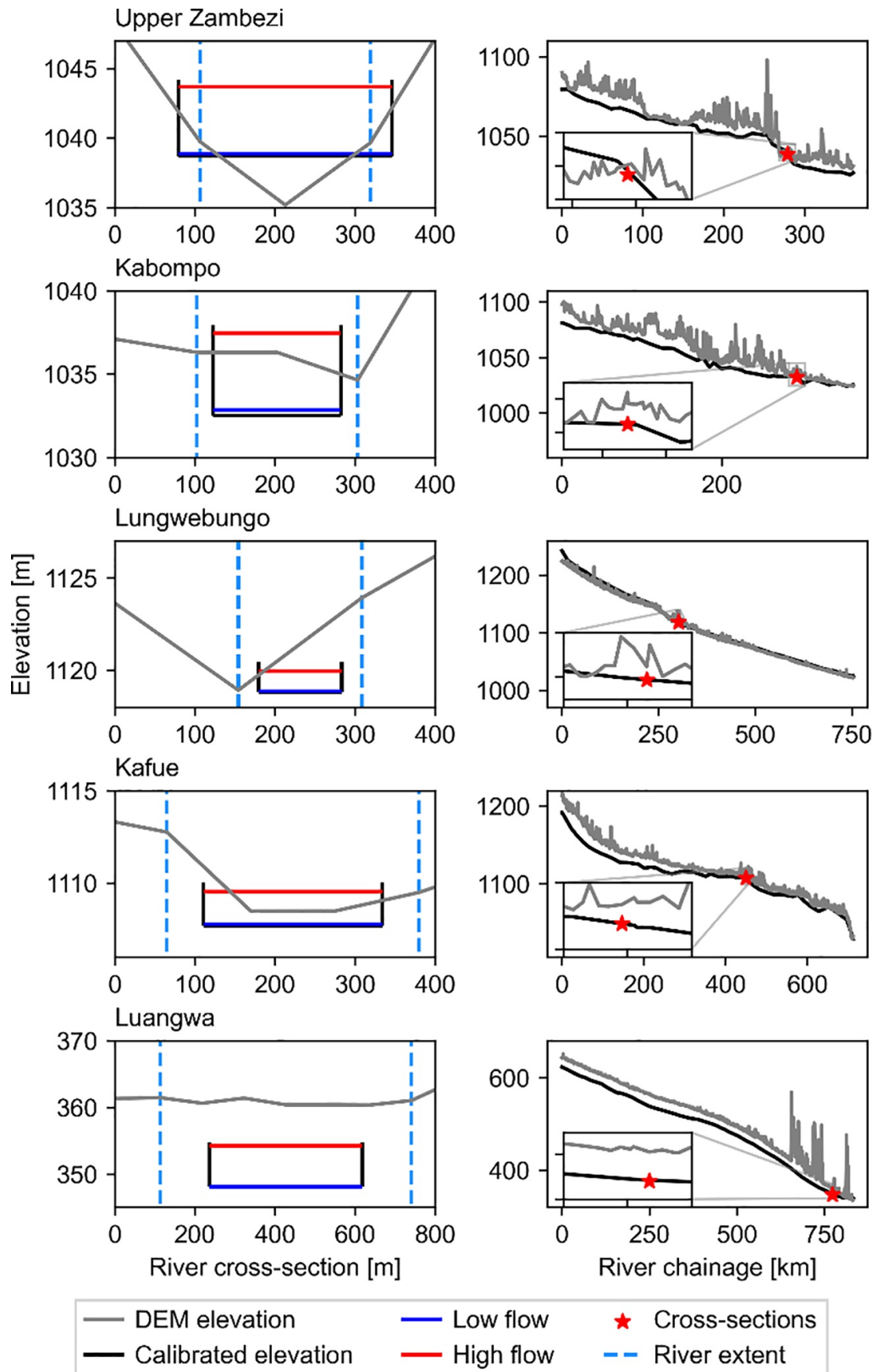

Figure 8. Selected calibrated river cross-sections versus Multi-Error-Removed Improved-Terrain Digital Elevation Model (MERIT DEM) bed and bank elevations (left) and calibrated bed elevation versus the MERIT DEM river surface longitudinal profiles (right).

it ensures that only coherent forcing/observation pairs are included in the calibration. The method enables filtering spatially dense WSE observations from geodetic satellite altimetry missions in data-sparse regions, where traditional outlier identification methods fail.

Hydraulic parameter retrieval was evaluated in synthetic experiments, focusing on the impacts of observation density and quality, and on the calibration setup. Bed elevation was retrieved with a RMSD of 42-75 cm and channel roughness with a RMSD of $0.007-0.009 \mathrm{~s} / \mathrm{m}^{1 / 3}$. The calibration revealed a higher sensitivity to the elevation offset compared to the roughness parameter, resulting in a poor retrieval of the upstream 
channel roughness. Furthermore, we noted the effect of the WSE observation density, with the most successful performance occurring in densely observed segments of the reach. Observation uncertainty affected the retrieval of parameters at ungauged cross-sections, and performance was more similar at gauged cross-sections for the three investigated data quality scenarios.

By carefully selecting observations where the steady-state assumption is reasonable, five reaches of the Zambezi were calibrated with satisfactory model performance using real CryoSat-2 observations. Calibration against real-world CryoSat-2 observations was evaluated using a range of statistical diagnostics to confirm model behavior and compared to Sentinel-3 and in situ observations of WSE to evaluate the temporal patterns of WSE in the river channels. The method yielded at least as good performance as past studies at far reduced computational cost and the parameter transfer from the steady-state to the transient solver did not impact performance significantly.

Geodetic altimetry missions clearly hold valuable information for hydrological studies, particularly in ungauged basins. However, the dense spatial sampling requires careful data selection and comes at a computational cost because, in the hydraulic inversion, WSE must be simulated at all points of observation by the hydraulic forward model. The approach presented in this study integrates the altimetry observations in a fast and efficient, global calibration approach at low cost compared to a 1D hydrodynamic model.

\section{Data Availability Statement}

The data can be requested from the ZRA for research purposes. The Sentinel-3 data used in this study can be freely processed on and downloaded from the ESA GPOD (Grid Processing on Demand SAR Versatile Altimetric Toolkit for Ocean Research and Exploitation) service (available on https://gpod.eo.esa.int/, last accessed October 14, 2020). The MERIT DEM used as reference elevation and in the river delineation was obtained from http://hydro.iis.u-tokyo.ac.jp/ yamadai/MERIT_DEM/ (last accessed October 14, 2020). The rainfall-runoff model source code is open source and part of the GlobWetland Africa QGIS Toolbox (available on http://globwetland-africa.org/?wpdmpro=globwetland-toolbox-1-5, last accessed November 17, 2020). LISFLOOD-FP can be accessed at http://www.bristol.ac.uk/geography/research/hydrology/models/lisflood/downloads/ (last accessed November 17, 2020). The CryoSat-2 observations and model parameters are available on Zenodo (doi:10.5281/zenodo.4899864).

Acknowledgments

The authors wish to thank the Zambezi River Authority (ZRA) for kindly providing the in situ observations in the Upper Zambezi used to evaluate the WSE simulations. The authors would like to thank the editor and the two anonymous reviewers.

\section{References}

Alsdorf, D. E., Rodríguez, E., \& Lettenmaier, D. P. (2007). Measuring surface water from space. Reviews of Geophysics, 45, 1-24. https://doi. org/10.1029/2006RG000197.1.INTRODUCTION

Berrisford, P., Dee, D. P., Poli, P., Brugge, R., Fielding, M., Fuentes, M., et al. (2011). The ERA-Interim archive Version 2.0 (p. 23 ). Retrieved from https://www.ecmwf.int/node/8174

Biancamaria, S., Bates, P. D., Boone, A., \& Mognard, N. M. (2009). Large-scale coupled hydrologic and hydraulic modelling of the Ob river in Siberia. Journal of Hydrology, 379(1-2), 136-150. https://doi.org/10.1016/j.jhydrol.2009.09.054

Boergens, E., Buhl, S., Dettmering, D., Klüppelberg, C., \& Seitz, F. (2017). Combination of multi-mission altimetry data along the Mekong River with spatio-temporal kriging. Journal of Geodesy, 91(5), 519-534. https://doi.org/10.1007/s00190-016-0980-z

Boergens, E., Nielsen, K., Andersen, O. B., Dettmering, D., \& Seitz, F. (2017). Water levels of the Mekong River Basin based on CryoSat-2 SAR data classification. Hydrology and Earth System Sciences Discussions(June), 1-22. https://doi.org/10.5194/hess-2017-217

De Almeida, G. A. M., Bates, P., Freer, J. E., \& Souvignet, M. (2012). Improving the stability of a simple formulation of the shallow water equations for 2-D flood modeling. Water Resources Research, 48(5), 1-14. https://doi.org/10.1029/2011WR011570

Dinardo, S., Fenoglio-Marc, L., Buchhaupt, C., Becker, M., Scharroo, R., Joana Fernandes, M., \& Benveniste, J. (2018). Coastal SAR and PLRM altimetry in German Bight and West Baltic Sea. Advances in Space Research, 62(6), 1371-1404. https://doi.org/10.1016/j. asr.2017.12.018

Domeneghetti, A., Tarpanelli, A., Brocca, L., Barbetta, S., Moramarco, T., Castellarin, A., \& Brath, A. (2014). The use of remote sensing-derived water surface data for hydraulic model calibration. Remote Sensing of Environment, 149, 130-141. https://doi.org/10.1016/j. rse.2014.04.007

Duan, Q., Sorooshian, S., \& Gupta, V. (1992). Effective and efficient global optimization for conceptual rainfall-runoff models. Water Resources Research, 28(4), 1015-1031. https://doi.org/10.1029/91wr02985

Durand, M., Neal, J., Rodríguez, E., Andreadis, K. M., Smith, L. C., \& Yoon, Y. (2014). Estimating reach-averaged discharge for the River Severn from measurements of river water surface elevation and slope. Journal of Hydrology, 511, 92-104. https://doi.org/10.1016/j. jhydrol.2013.12.050

ESA. (2017). Land cover CCI product user guide version 2. (Tech. Rep). Retrieved from elie.ucl.ac.be/CCI/viewer/download/ ESACCI-LC-Ph2-PUGv2_2.0.pdf

Frappart, F., Calmant, S., Cauhopé, M., Seyler, F., \& Cazenave, A. (2006). Preliminary results of ENVISAT RA-2-derived water levels validation over the Amazon basin. Remote Sensing of Environment, 100(2), 252-264. https://doi.org/10.1016/j.rse.2005.10.027 
Getirana, A. C. V., Boone, A., Yamazaki, D., \& Mognard, N. (2013). Automatic parameterization of a flow routing scheme driven by radar altimetry data : Evaluation in the Amazon basin. Water Resources Research, 49(1), 614-629. https://doi.org/10.1002/wrcr.20077

Gupta, H. V., Kling, H., Yilmaz, K. K., \& Martinez-Baquero, G. F. (2009). Decomposition of the Mean Squared Error \& NSE Performance Criteria: Implications for Improving Hydrological Modelling. Journal of Hydrology, 377(1-2), 80-91. https://doi.org/10.1016/j. jhydrol.2009.08.003

Hannah, D. M., Demuth, S., van Lanen, H. A. J., Looser, U., Prudhomme, C., Rees, G., et al. (2011). Large-scale river flow archives: Importance, current status and future needs. Hydrological Processes, 25(7), 1191-1200. https://doi.org/10.1002/hyp.7794

Houska, T., Kraft, P., Chamorro-Chavez, A., \& Breuer, L. (2015). SPOTting model parameters using a ready-made python package. PloS One, 10(12), 1-22. https://doi.org/10.1371/journal.pone.0145180

Huffman, G., Bolvin, D., Braithwaite, D., Hsu, K., Joyce, R., \& Xie, P. (2014). Integrated multi-satellitE retrievals for GPM (IMERG), version 4.4. NASA's Precipitation Processing Center. Retrieved from ftp://arthurhou.pps.eosdis.nasa.gov/gpmdata/

Jiang, L., Madsen, H., \& Bauer-Gottwein, P. (2019). Simultaneous calibration of multiple hydrodynamic model parameters using satellite altimetry observations of water surface elevation in the Songhua River. Remote Sensing of Environment, 225, 229-247. https://doi. org/10.1016/j.rse.2019.03.014

Jiang, L., Nielsen, K., Andersen, O. B., \& Bauer-Gottwein, P. (2017). CryoSat-2 radar altimetry for monitoring freshwater resources of China. Remote Sensing of Environment, 200(August), 125-139. https://doi.org/10.1016/j.rse.2017.08.015

Kittel, C. M. M., Arildsen, A. L., Dybkjær, S., Hansen, E. R., Linde, I., Slott, E., et al. (2020). Informing hydrological models of poorly gauged river catchments-A parameter regionalization and calibration approach. Journal of Hydrology, 587. https://doi.org/10.1016/j. jhydrol.2020.124999

Kittel, C. M. M., Jiang, L., Tøttrup, C., \& Bauer-Gottwein, P. (2021). Sentinel-3 radar altimetry for river monitoring - A catchment-scale evaluation of satellite water surface elevation from Sentinel-3A and Sentinel-3B. Hydrology and Earth System Sciences, 25(1), 333-357. https://doi.org/10.5194/hess-25-333-2021

Kittel, C. M. M., Nielsen, K., Tøttrup, C., \& Bauer-Gottwein, P. (2018). Informing a hydrological model of the Ogooué with multi-mission remote sensing data. Hydrology and Earth System Sciences, 22, 1453-1472. https://doi.org/10.5194/hess-22-1453-2018

Liu, G., Schwartz, F. W., Tseng, K.-H., \& Shum, C. K. (2015). Discharge and water-depth estimates for ungauged rivers: Combining hydrologic, hydraulic, and inverse modeling with stage and water-area measurements from satellites. Water Resouces Research, 51, $6017-6035$. https://doi.org/10.1002/2015WR017200.A10.1002/2015wr016971

Mahé, G., Lienou, G., Descroix, L., Bamba, F., Paturel, J. E., Laraque, A., et al. (2013). The rivers of Africa: Witness of climate change and human impact on the environment. Hydrological Processes, 27(15), 2105-2114. https://doi.org/10.1002/hyp.9813

Maillard, P., Bercher, N., \& Calmant, S. (2015). New processing approaches on the retrieval of water levels in Envisat and SARAL radar altimetry over rivers: A case study of the São Francisco River, Brazil. Remote Sensing of Environment, 156, 226-241. https://doi. org/10.1016/j.rse.2014.09.027

Michailovsky, C. I., \& Bauer-Gottwein, P. (2014). Operational reservoir inflow forecasting with radar altimetry: The Zambezi case study. Hydrology and Earth System Sciences, 18(3), 997-1007. https://doi.org/10.5194/hess-18-997-2014

Myers, E., Hess, K., Yang, Z., Xu, J., Wong, A., Doyle, D., et al. (2007). VDatum and strategies for national coverage. Oceans Conference Record (IEEE). https://doi.org/10.1109/OCEANS.2007.4449348

Neal, J. C., Odoni, N. A., Trigg, M. A., Freer, J. E., Garcia-Pintado, J., Mason, D. C., et al. (2015). Efficient incorporation of channel cross-section geometry uncertainty into regional and global scale flood inundation models. Journal of Hydrology, 529, 169-183. https://doi. org/10.1016/j.jhydrol.2015.07.026

Neal, J. C., Schumann, G., \& Bates, P. (2012). A subgrid channel model for simulating river hydraulics and floodplain inundation over large and data sparse areas. Water Resources Research, 48(W11506), 1-16. https://doi.org/10.1029/2012WR012514

Nielsen, K., Stenseng, L., Andersen, O. B., Villadsen, H., \& Knudsen, P. (2015). Validation of CryoSat-2 SAR mode based lake levels. Remote Sensing of Environment, 171, 162-170. https://doi.org/10.1016/j.rse.2015.10.023

O’Loughlin, F., Trigg, M. A., Schumann, G. J. P., \& Bates, P. D. (2013). Hydraulic characterization of the middle reach of the Congo River. Water Resources Research, 49(8), 5059-5070. https://doi.org/10.1002/wrcr.20398

O’Loughlin, F. E., Neal, J., Schumann, G. J. P., Beighley, E., \& Bates, P. D. (2020). A LISFLOOD-FP hydraulic model of the middle reach of the Congo. Journal of Hydrology, 580(September 2019), 124203. https://doi.org/10.1016/j.jhydrol.2019.124203

Paiva, R. C. D., Collischonn, W., Bonnet, M. P., De Gonçalves, L. G. G., Calmant, S., Getirana, A., \& Santos Da Silva, J. (2013). Assimilating in situ and radar altimetry data into a large-scale hydrologic-hydrodynamic model for streamflow forecast in the Amazon. Hydrology and Earth System Sciences, 17, 2929-2946. https://doi.org/10.5194/hess-17-2929-2013

Paris, A., Dias de Paiva, R., Santos Da Silva, J., Medeiros Moreira, D., Calmant, S., Garambois, P.-A., et al. (2016). Stage-discharge rating curves based on satellite altimetry and modeled discharge in the Amazon basin. Water Resources Research, 53, 3787-3814. https://doi. org/10.1002/2014WR016618.Received

Pekel, J.-F., Cottam, A., Gorelick, N., \& Belward, A. S. (2016). High-resolution mapping of global surface water and its long-term changes. Nature, 540(7633), 418-422. https://doi.org/10.1038/nature20584

Pool, S., Vis, M., \& Seibert, J. (2018). Evaluating model performance: Towards a non-parametric variant of the Kling-Gupta efficiency. Hydrological Sciences Journal, 63(13-14), 1941-1953. https://doi.org/10.1080/02626667.2018.1552002

Saltelli, A., Tarantola, S., \& Chan, K. P. (1999). A quantitative model-independent method for global sensitivity analysis of model output. Technometrics, 41(1), 39-56. https://doi.org/10.1080/00401706.1999.10485594

Schneider, R., Godiksen, P. N., Villadsen, H., Madsen, H., \& Bauer-Gottwein, P. (2017). Application of CryoSat-2 altimetry data for river analysis and modelling. Hydrology and Earth System Sciences, 21, 751-764. https://doi.org/10.5194/hess-21-751-2017

Schneider, R., Ridler, M. E., Godiksen, P. N., Madsen, H., \& Bauer-Gottwein, P. (2018). A data assimilation system combining CryoSat-2 data and hydrodynamic river models. Journal of Hydrology, 557, 197-210. https://doi.org/10.1016/j.jhydrol.2017.11.052

Schneider, R., Tarpanelli, A., Nielsen, K., Madsen, H., \& Bauer-Gottwein, P. (2018). Evaluation of multi-mode CryoSat-2 altimetry data over the Po River against in situ data and a hydrodynamic model. Advances in Water Resources, 112, 17-26. https://doi.org/10.1016/j. advwatres.2017.11.027

Schumann, G., Di Baldassarre, G., Alsdorf, D., \& Bates, P. D. (2010). Near real-time flood wave approximation on large rivers from space: Application to the River Po, Italy. Water Resources Research, 46(5), 1-8. https://doi.org/10.1029/2008WR007672

Schwatke, C., Dettmering, D., Bosch, W., \& Seitz, F. (2015). DAHITI-An innovative approach for estimating water level time series over inland waters using multi-mission satellite altimetry. Hydrology and Earth System Sciences, 19(10), 4345-4364. https://doi.org/10.5194/hess-19-4345-2015 
Sosa, J., Sampson, C., Smith, A., Neal, J., \& Bates, P. (2020). A toolbox to quickly prepare flood inundation models for LISFLOOD-FP simulations. Environmental Modelling \& Software, 123(October 2019), 104561. https://doi.org/10.1016/j.envsoft.2019.104561

Tarboton, D. (2015). TauDEM version 5. Hydrology Research Group, Utah State University. Retrieved from http://hydrology.usu.edu/ taudem/taudem5/documentation.html

Tourian, M. J., Tarpanelli, A., Elmi, O., Qin, T., Brocca, L., Moramarco, T., \& Sneeuw, N. (2016). Spatiotemporal densification of water level time series by multimission satellite altimetry. Water Resources Research, 52, 613-615. https://doi.org/10.1002/2015wr017654

Villadsen, H., Deng, X., Andersen, O. B., Stenseng, L., Nielsen, K., \& Knudsen, P. (2016). Improved inland water levels from SAR altimetry using novel empirical and physical retrackers. Journal of Hydrology, 537, 234-247. https://doi.org/10.1016/j.jhydrol.2016.03.051

Vörösmarty, C., Askew, A., Grabs, W., Barry, R. G., Birkett, C., Döll, P., et al. (2001). Global water data: A newly endangered species. Eos, 82(5), 54-58. https://doi.org/10.1029/01EO00031

Westerberg, I. K., Guerrero, J. L., Younger, P. M., Beven, K. J., Seibert, J., Halldin, S., et al. (2011). Calibration of hydrological models using flow-duration curves. Hydrology and Earth System Sciences, 15(7), 2205-2227. https://doi.org/10.5194/hess-15-2205-2011

Wood, M., Hostache, R., Neal, J., Wagener, T., Giustarini, L., Chini, M., et al. (2016). Calibration of channel depth and friction parameters in the LISFLOOD-FP hydraulic model using medium-resolution SAR data and identifiability techniques. Hydrology and Earth System Sciences, 20(12), 4983-4997. https://doi.org/10.5194/hess-20-4983-2016

Yamakazi, D., Ikeshima, D., Tawatari, R., Yamaguchi, T., O’Loughlin, F., Neal, J. C., et al. (2017). A high-accuracy map of global terrain elevations Dai. Geophysical Research Letters, 44, 5844-5853. https://doi.org/10.1002/2017GL072874

Zhang, L., Potter, N., Hickel, K., Zhang, Y., \& Shao, Q. (2008). Water balance modeling over variable time scales based on the Budyko framework-Model development and testing. Journal of Hydrology, 360, 117-131. https://doi.org/10.1016/j.jhydrol.2008.07.021

Zhang, X., Jiang, L., Kittel, C. M. M., \& Yao, Z. (2020). On the performance of Sentinel-3 altimetry over new reservoirs : Approaches to determine on-board a-priori elevation. Geophysical Research Letters, 47(17), 1-11. https://doi.org/10.1029/2020GL088770 